\title{
Cluster observations of continuous reconnection at the magnetopause under steady interplanetary magnetic field conditions
}

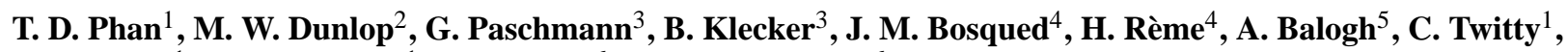 \\ F. S. Mozer ${ }^{1}$, C. W. Carlson ${ }^{1}$, C. Mouikis ${ }^{6}$, and L. M. Kistler ${ }^{6}$ \\ ${ }^{1}$ Space Science Laboratory, Berkeley, USA \\ ${ }^{2}$ Rutherford Laboratory, Oxford, UK \\ ${ }^{3}$ Max-Planck-Institut für extraterrestrische Physik, Garching, Germany \\ ${ }^{4}$ Centre d'Etude Spatiale des Rayonnements, Toulouse, France \\ ${ }^{5}$ Imperial College, London, UK \\ ${ }^{6}$ University of New Hampshire, Durham, NH, USA
}

Received: 1 October 2003 - Revised: 16 January 2004 - Accepted: 3 February 2004 - Published: 14 July 2004

Part of Special Issue "Spatio-temporal analysis and multipoint measurements in space"

\begin{abstract}
On 26 January 2001, the Cluster spacecraft detected high-speed plasma jets at multiple crossings of the high-latitude duskside magnetopause (MP) and boundary layer (BL) over a period of more than $2 \mathrm{~h}$. The 4 spacecraft combined spent more than half of this time in the MP/BL and jets were observed whenever a spacecraft was in the MP. These observations were made under steady southward and dawnward interplanetary magnetic field (IMF) conditions. The magnetic shear across the local MP was $\sim 100^{\circ}$ and $\beta \sim 1$ in the adjacent magnetosheath. The jet velocity is in remarkable agreement with reconnection prediction throughout the entire interval, except for one crossing that had no ion measurements inside the current layer. The flow speed measured in the deHoffmann Teller frame is $90 \%$ of the Alfvén speed on average for the 10 complete MP current layer crossings that are resolved by the ion measurements. These findings strongly suggest that reconnection was continuously active for more than two hours. The jets were directed persistently in the same northward and anti-sunward direction, implying that the $\mathrm{X}$-line was always below the spacecraft. This feature is inconsistent with patchy and random reconnection or convecting multiple $\mathrm{X}$-lines. The majority of MP/BL crossings in this two-hour interval were partial crossings, implying that they are caused by bulges sliding along the MP, not by inward-outward motion of a uniformly thin MP/BL. The presence of the bulges suggests that, although reconnection is continuously active under steady IMF conditions, its rate may be modulated. The present investigation also reveals that (1) the predicted ion D-shaped distributions are absent in all reconnection jets on this day, (2) the electric field fluctuations are larger in the reconnecting MP than in the magnetosheath proper, but their amplitudes never exceed $20 \mathrm{mV} / \mathrm{m}$, (3) the ion-electron differential motion is $\sim 20 \mathrm{~km} / \mathrm{s}$ for the
\end{abstract}

Correspondence to: T. D. Phan

(phan@ssl.berkeley.edu) observed MP current density of $\sim 50 \mathrm{nA} / \mathrm{m}^{2}$ (deduced from $\nabla \times \mathbf{B}$ ), thus inconsequential for the deHoffmann-Teller and Walén analyses, (4) flows in an isolated flux transfer event (FTE) are directed in the same direction as the MP jets and satisfy the Walén relation, suggesting that this FTE is also generated by reconnection. Finally, the present event cannot be used to evaluate the validity of component or anti-parallel merging models because, although the magnetic shear at the local MP was $\sim 100^{\circ}\left(\ll 180^{\circ}\right)$, the X-line may be located more than $9 R_{E}$ away (in the opposite hemisphere), where the shear could be substantially different.

Key words. Magnetospheric physics (magnetopause, cusp, and boundary layers; solar wind-magnetosphere interactions) - Space plasma physics (magnetic reconnection)

\section{Introduction}

Magnetic reconnection is a dominant process that allows the solar wind to cross the magnetopause (MP) and to enter the magnetosphere (e.g. Cowley, 1984). While single-spacecraft measurements have provided ample in-situ evidence for the occurrence of reconnection at the MP (e.g. Paschmann et al., 1979, 1986; Sonnerup et al., 1981; Gosling et al., 1991; Smith and Rodgers, 1991; Fuselier et al., 1991; Onsager et al., 2001; Avanov et al., 2001; Mozer et al., 2002), little is known about the large-scale spatial and temporal nature of reconnection from single-point in-situ observations. For example, it is not known whether reconnection at the MP is intrinsically intermittent or continuous. As the name implies, intermittent reconnection turns on and off. In contrast, continuous reconnection can have variable rates but never ceases. When the rate is nearly constant, the process is termed quasi-steady. 


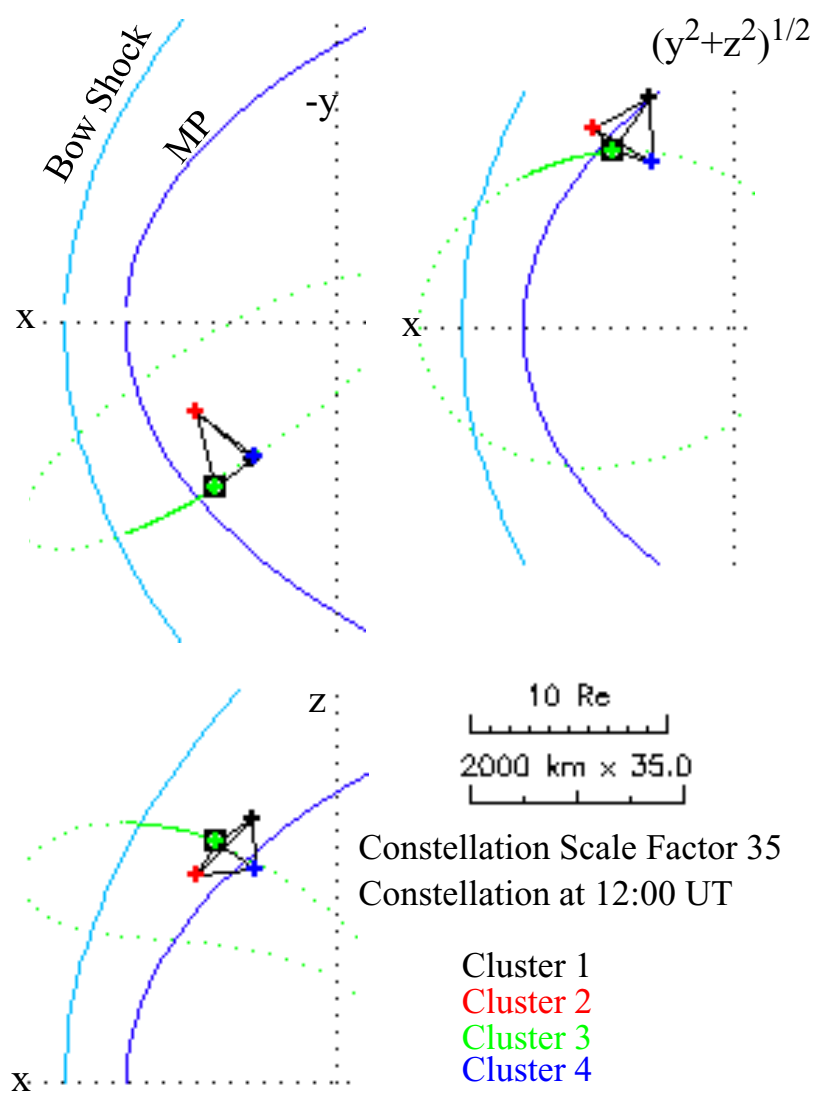

Fig. 1. Cluster orbits at the high-latitude dusk flank MP. The spacecraft separation is $\sim 650 \mathrm{~km}$. Spacecraft 1,2 , and 3 are roughly in the same plane tangential to the MP. Spacecraft 4 is earthward of the other 3 spacecraft. Figure adapted from CSDSWEB.

Frequent observations at the Earth's MP of flux transfer events (FTE) (Russell and Elphic, 1978), poleward moving auroral forms (e.g. Farrugia et al., 1998) or steps in the ion dispersion signatures seen in the magnetospheric cusps at low-altitudes (e.g. Lockwood et al., 2003) have been interpreted as signatures of intermittent reconnection. However, many of these studies were not strictly confined to steady solar wind conditions. Thus, the fundamental question is whether reconnection is always intermittent, even under steady boundary conditions.

There have been attempts to deduce the steadiness of reconnection based on in-situ MP observations. Repeated encounters of reconnection jets at multiple MP crossings have been interpreted as evidence for continuous reconnection (e.g. Gosling et al., 1982; Phan et al., 2000). However, because signatures of reconnection are localized in the thin MP, they can be observed only for a short time when a spacecraft crosses the layer. Typical crossing times are only a few minutes and the crossings are often far apart in time. Therefore, one could never be sure whether reconnection had actually stopped in between successive MP crossings.
Recently, remote sensing methods using radar (e.g. Pinnock et al., 2003) and proton aurora images (e.g. Frey et al., 2003) have provided indirect evidence for continuous reconnection lasting many hours. These are powerful tools to remotely monitor the large-scale behavior of reconnection. However, the interpretations based on remote sensing methods need to be confirmed by in-situ measurements at the MP.

Here we report multi-spacecraft observations of reconnection jets at the MP that would indicate continuous reconnection for more than two hours under steady IMF conditions. The investigation of reconnection under steady conditions is important because it reveals the fundamental nature of reconnection without the contaminations and complications resulting from rapid variations of the boundary conditions surrounding the MP.

The organization of the paper is as follows. In Sect. 2 the spacecraft orbit and the data sets used are briefly described. The observations are described in Sect. 3. In Sect. 4 we compare the jet velocity with the expectation from reconnection in 3 different ways to demonstrate the robustness of the results. We discuss the implications of the observations and of the Walén test results in Sect. 5. In Sect. 6 we summarize the observations and interpretations. Some aspects of this event have been shown by Bosqued et al. (2001).

\section{Instrumentation and orbits}

This study uses data from the Cluster ion composition (CIS) (Reme et al., 2001), magnetic field (FGM) (Balogh et al., 2001) and electric field (EFW) (Gustafsson et al., 2001) experiments. The CIS experiments obtain full threedimensional ion distributions with high-time resolution (one 4-s spacecraft spin) and with mass-per-charge composition determination. CIS comprises of two different instruments, a Hot Ion Analyser (HIA) (with energies from $5 \mathrm{eV}$ to $32 \mathrm{keV}$ ) and a time-of-flight ion Composition Distribution Function (CODIF) analyzer (with energies from $20 \mathrm{eV}$ to $38 \mathrm{keV}$ ). CODIF provides information on the presence of $\mathrm{He}^{+}, \mathrm{He}^{++}$, and $\mathrm{O}^{+}$. The CIS instruments are operative on only 3 of the Cluster spacecraft. The magnetic field is measured at much higher rates but for the present investigation spin-average (4s) data will be used. The electric field for this event was measured at 25 samples/s. Solar wind parameters are obtained by the ACE spacecraft. Level 2 data from the ACE science center website are used.

The Cluster-II orbits are highly elongated polar orbits with apogee at $\sim 19.6 R_{E}$ and perigee at $\sim 4 R_{E}$. On 26 January 2001 , the separation distances between the spacecraft was $\sim 650 \mathrm{~km}$. The series of MP crossings described in this paper occurred at $\sim 16 \mathrm{MLT}$, radial distance of $\sim 13 R_{E}$, and magnetic latitude of $46^{\circ}$, or $\sim 9.5 R_{E}$ above the magnetic equator (see Fig. 1). 


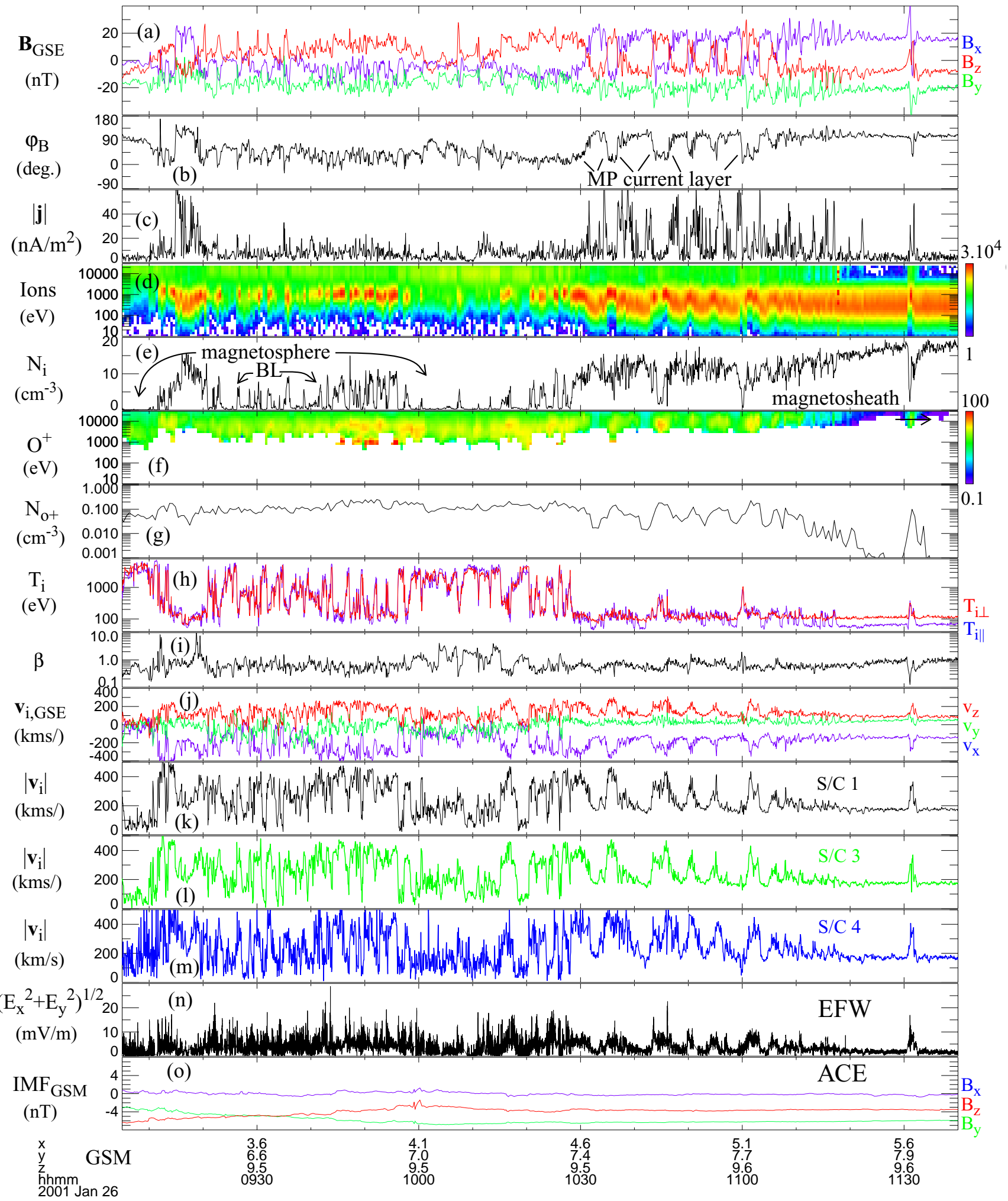

Fig. 2. Panels a-n display measurements in the magnetosphere/MP/magnetosheath from Cluster spacecraft 1 except noted. Panel o shows ACE solar wind magnetic field data. (a) Magnetic field components in GSE, (b) magnetic field angle in the plane tangential to the MP with zero degree approximately along GSM z, (c) current density computed from $\nabla \times \mathbf{B}$ using $\mathbf{B}$ from all 4 spacecraft, (d) ion energy-time spectrogram (in eVs $\mathrm{eV}^{-1} \mathrm{~cm}^{-2} \mathrm{ster}^{-1} \mathrm{eV}^{-1}$ ), (e) ion number density, (f) $\mathrm{O}^{+}$spectrogram, (g) $\mathrm{O}^{+}$number density, (h) perpendicular (red) and parallel (purple) ion temperatures, (i) plasma $\beta$, (j) ion flow components in GSE, (k)-(m) ion flow speed from spacecraft 1, 3, and 4, respectively, (n) electric field magnitude $\left(\mathrm{E}_{x}^{2}+\mathrm{E}_{y}^{2}\right)^{1 / 2},(\mathbf{o})$ interplanetary magnetic field components in GSM. 


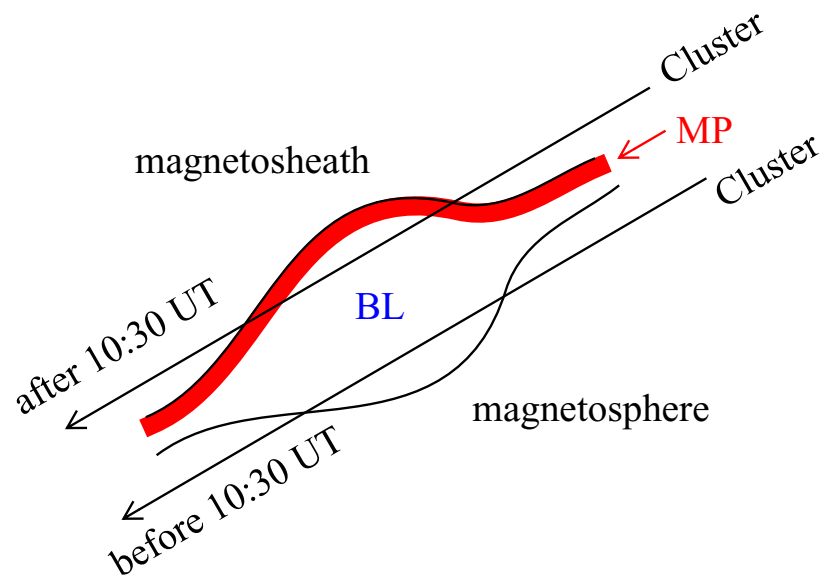

Fig. 3. Effective partial crossings by Cluster through the MP/BL before and after 10:30 UT. Most crossings before 10:30 UT encountered the BL but did not encounter the MP and magnetosheath whereas crossings after 10:30 UT encountered the MP and BL but did not encounter the magnetosphere, implying travelling blobs.

\section{Observations}

Figure 2 shows the Cluster outbound pass through the highlatitude $\left(46^{\circ}\right)$ dusk flank (16 MLT) MP that occurred on 26 January 2001. As the spacecraft went from the magnetosphere to the magnetosheath, they encountered the MP current layer and boundary layer (BL) multiple times over a period of more than $2 \mathrm{~h}$ (from 09:10 UT to 11:30 UT). The MP current layer is identified by the large field rotation from its southward $\left(\mathrm{B}_{z}<0\right)$ to its northward $\left(\mathrm{B}_{z}>0\right)$ orientation (Fig. 2a). The BL is the intermediate density (Fig. 2e) and temperature (Fig. 2h) region earthward of the MP current layer. As will be discussed in more detail later, the BL region could be the slow-mode expansion fan region (earthward of the rotational discontinuity) of the reconnection layer in this high magnetic shear and asymmetric reconnection situation (Levy et al., 1964).

During the first part of this 2-hour interval (09:10 UT10:30 UT), with the exception of two complete crossings from the magnetosphere to the magnetosheath at 09:15 and 09:18 UT, all the other crossings were partial crossings into the inner part of the BL from the magnetosphere. During these excursions, the spacecraft did not encounter the MP current layer nor exit into the magnetosheath (Fig. 2a). This is evidenced by the fact that the spacecraft encountered only the intermediate density and temperature region - the $\mathrm{BL}-$ without crossing the field rotation region. After 10:30 UT it is the other way around. With the exception of the complete MP/BL crossing at 11:00 UT, when the density reached the low magnetospheric value, all other crossings observed field rotations associated with the MP current layer but the spacecraft never reached the low-density $\left(<1 \mathrm{~cm}^{-3}\right)$ magnetosphere. These are thus complete crossings of the current layer but partial entries into the BL.

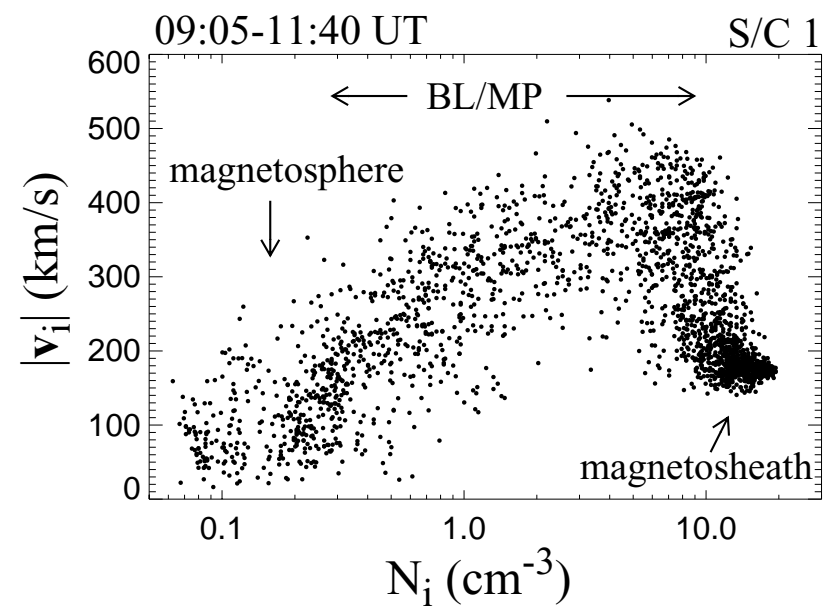

Fig. 4. Scatter plot of spacecraft 1 ion flow speed as a function of ion number density for the entire 2.5 -h pass. The flows in the $\mathrm{MP} /$ outer BL are enhanced relative to magnetosheath flows, with no exceptions.

The fact that most crossings (approaching from both the magnetosphere and the magnetosheath) are partial, even though the spacecraft had traveled $2 R_{E}$ in radial distance in $2 \mathrm{~h}$, would not be consistent with the simple inward-outward motion of a uniformly thin MP. This finding implies instead that the MP/BL crossings are caused by bulges convecting along the MP and that these structures bulge toward both the magnetosphere and the magnetosheath (see Fig. 3). In Sect. 5.2 we suggest that these bulges could be the result of variable reconnection rates.

The solar wind density and temperature were steady during this 2-h interval (not shown). The IMF was slowly varying from 9:00 UT to 10:00 UT, and became remarkably steady from 10:00 to 11:40 UT (Fig. 2o). The IMF $B_{z}$ and $\mathrm{B}_{y}$ were both negative during the entire pass, with $\mathrm{B}_{y}$ being the dominant component after 10:00 UT. IMF $\mathrm{B}_{x}$ is approximately 0 throughout. Thus, the magnetic shear (Fig. 2b) was $\sim 140^{\circ}$ at the 09:15 and 09:18 UT MP and became smaller $\left(\sim 100^{\circ}\right)$ and remained at this value after 10:00 UT.

One striking feature of this MP pass is the persistent presence of high-speed plasma jets at the MP detected by all spacecraft over the entire 2-h interval (Fig. 2k-m). The flow speed enhancements across the MP (relative to the magnetosheath flows) are slightly more than $200 \mathrm{~km} / \mathrm{s}$. The instances where the flow speed drops to below the magnetosheath value correspond to times when the spacecraft reached the inner BL or the magnetosphere proper. To illustrate this point further, Fig. 4 shows a scatter plot of the flow speed as a function of the density for the 2.5 -h interval plotted in Fig. 2. The figure shows that the flows in the MP/BL, where the density is intermediate between magnetosheath and magnetosphere values, say between 10 and $2 \mathrm{~cm}^{-3}$, is enhanced compared to the magnetosheath flows. The fact that the flow speed never falls below the magnetosheath value throughout this density range indicates that 
the plasma jets were detected at all crossings with available measurements inside the MP/outer BL. If jets were absent at some $\mathrm{MP} /$ outer $\mathrm{BL}$, there would have been data points below $200 \mathrm{~km} / \mathrm{s}$ in the $2-10 \mathrm{~cm}^{-3}$ density range. Note that this flow speed versus density profile is in stark contrast to the monotonic decrease of the flow speed with decreasing density for the low-shear MP when reconnection is not occurring at the local MP (e.g. Paschmann et al., 1993; Phan et al., 1997).

Figure $2 \mathrm{j}$ shows that the flow enhancements are persistently in the same direction, northward $\left(\Delta \mathrm{v}_{z}>0\right)$ and tailward $\left(\Delta \mathrm{v}_{x}<0\right)$ for all MP crossings.

Figures $2 \mathrm{f}-\mathrm{g}$ show the presence of high-energy $(3-30 \mathrm{keV})$ $\mathrm{O}^{+}$of magnetospheric origin in every jet. The $\mathrm{O}^{+}$are absent in the magnetosheath proper (after 11:35UT). The presence of $\mathrm{O}^{+}$in the jets would be consistent with this region being on open field lines (and connected to the magnetospheric $\mathrm{O}^{+}$ source). The $\mathrm{O}^{+}$density in the jets $\left(\sim 0.2-0.3 \mathrm{~cm}^{-3}\right)$ is similar to that in the magnetosphere, which suggests further that the field lines are newly opened - i.e. reconnection is active. The $0.2-0.3 \mathrm{~cm}^{-3} \mathrm{O}^{+}$density represents $\sim 2 \%$ of total ion number density of the magnetosheath.

Figure $2 \mathrm{n}$ shows high-resolution (25 samples/s) electric field data. The electric field amplitudes (based on the measured $\mathrm{x}$ and $\mathrm{y}$ components) in the jets are slightly larger than in the magnetosheath proper, but never exceeded $20 \mathrm{mV} / \mathrm{m}$.

The MP current density is typically $\sim 50 \mathrm{nA} / \mathrm{m}^{2}$ (Fig. 2c). The current density is computed from $\nabla \times \mathbf{B}$ using magnetic field measurements from all 4 spacecraft (Dunlop et al., 2002).

Finally, besides the MP crossings, there were two isolated encounters with flux transfer events (FTE) at 11:30 and 12:10 UT (not shown), together with a train of smaller amplitude FTEs (11:05-11:25 UT). The key FTE signature is bipolar $\mathrm{B}_{N}$ (Russell and Elphic, 1978). The magnetic field strength of the 11:30 UT FTE is strongly enhanced (>50 nT). The flow jets in this FTE are directed in the same direction as jets at the MP. This large FTE event has been discussed in more detail in terms of its structures by Bosqued et al. (2001).

In what follows we will first show that the plasma jets at the MP/BL are consistent with reconnection. We then discuss the implications of our observations for continuous reconnection and for the structure of the MP.

\section{Shear-stress balance tests}

According to magnetohydrodynamic models of reconnection at the dayside MP involving high density plasma on the magnetosheath side and low density on the magnetospheric side, the reconnecting MP can be described as a rotational discontinuity (RD) (Levy et al., 1964). Across this discontinuity, the solar wind plasma is accelerated by the magnetic field tension force from the magnetic kink resulting from the linkage between magnetosheath and magnetospheric fields. Thus in 1-D, steady-state MP reconnection, the flow acceleration is predicted to be precisely Alfvénic.
In this section, we perform the shear-stress balance tests (e.g. Paschmann et al., 1986; Sonnerup et al., 1987) to examine the occurrence of Alfvénic flow acceleration at each of the MP encounters. It is emphasized that this test should be performed across the full magnetic field rotation at the MP in order to examine the presence of a large standing Alfvén wave (the rotational discontinuity) at the MP, which implies magnetic connectivity between the two plasmas on the two sides of the MP. Analyses on small amplitude variations of the field on either side of the MP would only reveal the presence of small ripples on the MP and not reconnection. The results of our qualitative (Sect. 4.1) as well as quantitative (Sects 4.2 and 4.3) analyses confirm to high precision that the $\mathrm{RD}$ (presumably associated with reconnection) is the source of the jets described in Sect. 3 .

\subsection{Qualitative assessment of the Alfvénic nature of jets}

First, one can perform a simple test to see whether the flow change across the MP is consistent with the predicted change according to the rotational discontinuity relation $\Delta \mathbf{v} \sim \pm \Delta \mathbf{B}\left(\mu_{0} \rho_{\text {sheath }}\right)^{-1 / 2}$, where the positive or negative sign of this relation depends on whether the observation point is north or south of the reconnection site. The pressure anisotropy effect (included in the more quantitative analyses below) is omitted here for simplicity. From Figs. 2a and $2 \mathrm{j}$, one can see that the changes in the flow components are correlated (in phase) with the field change $\left(\Delta \mathrm{B}_{x}\right.$ and $\Delta \mathrm{v}_{x}$ are both negative and $\Delta \mathrm{v}_{z}$ and $\Delta \mathrm{B}_{z}$ are positive). The $\mathrm{y}$ components of the flow and magnetic field do not vary much across the MP since they are roughly along the MP normal. The $\Delta \mathrm{B}_{z}$ across the MP is of the order of $28 \mathrm{nT}(-8 \mathrm{nT}$ in the magnetosheath and $20 \mathrm{nT}$ in the magnetosphere). With a magnetosheath density of $\sim 13 \mathrm{~cm}^{-3}$, the predicted change of the $z$ component of the Alfvén velocity across the MP is $\sim 170 \mathrm{~km} / \mathrm{s}$. This is comparable to the measured $\mathrm{V}_{z}$ change of $160 \mathrm{~km} / \mathrm{s}(100 \mathrm{~km} / \mathrm{s}$ in magnetosheath and $260 \mathrm{~km} / \mathrm{s}$ in MP). For the $x$ component, the predicted flow change based on a $\Delta \mathrm{B}_{x}$ of $29 \mathrm{nT}(-19 \mathrm{nT}$ in sheath and $10 \mathrm{nT}$ in sphere) is $175 \mathrm{~km} / \mathrm{s}$, again comparable to the observed flow change of $170 \mathrm{~km} / \mathrm{s}$ ( -150 in magnetosheath and -320 in MP). The persistent positive correlation (as opposed to sometimes anticorrelation) between $\Delta \mathbf{v}$ and $\Delta \mathbf{B}$, as well as the positive $\mathrm{v}_{z}$ and negative $\mathrm{v}_{x}$ enhancements, indicate that the normal magnetic field $\left(\mathrm{B}_{N}\right)$ points earthward and the X-line is southward and sunward of the spacecraft at all times.

4.2 Predicted and observed time series of jets based on a single magnetosheath reference point

Figure 5 shows a more quantitative assessment of the agreement between predicted and observed flows for the 10:10 11:40 UT interval - which encompasses more than 10 partial or complete MP crossings and an FTE (at 11:30 UT). The predicted velocities are computed based on a single reference magnetosheath time (10:41 UT) marked by the dashed line. The flow prediction is based on the local magnetic 


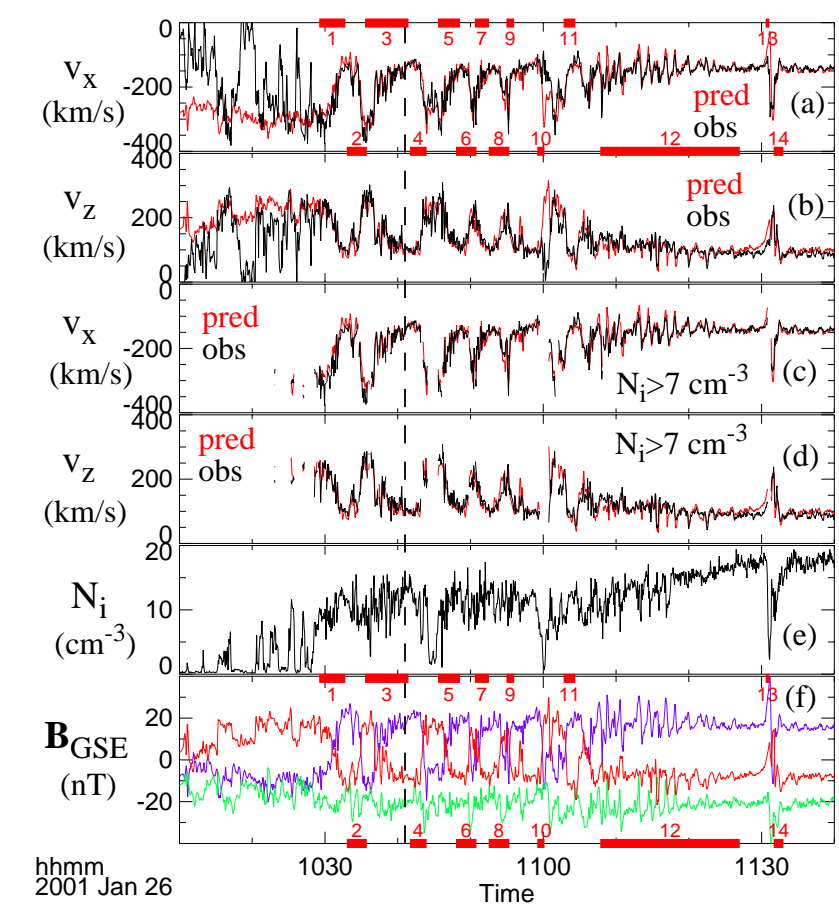

Fig. 5. Zoom-in of the 10:10-11:40 UT interval. (a)-(b) $x$ and $z$ components of the predicted (red) and observed ion velocity, (c)-(d) same as panels (a) and (b) but for ion density $>7 \mathrm{~cm}^{-3}$ only, (e) ion number density, (f) magnetic field components in GSE. The labeled crossing numbers in panels (a) and (f) correspond to complete or near-complete crossings for the Walén test summarized in Table 1. The dashed line denotes the magnetosheath reference time.

field measurements and the reference velocity and field values: $\quad \Delta \mathbf{v}_{\text {predicted }}=\mathbf{v}_{2 t}-\mathbf{v}_{1 t}=+\left(1-\alpha_{1}\right)^{1 / 2}\left(\mu_{0} \rho_{1}\right)^{-1 / 2}\left[\mathbf{B}_{2 t}(1-\right.$ $\left.\left.\alpha_{2}\right) /\left(1-\alpha_{1}\right)-\mathbf{B}_{1 t}\right]$ (Hudson, 1970; Paschmann et al., 1986). The positive sign was chosen based on the observed positive correlation between $\Delta \mathbf{v}$ and $\Delta \mathbf{B}$ at the MP. Subscript " 1 " denotes the reference time and " 2 " denotes the prediction for all other times. The pressure anisotropy factor is $\alpha\left(\mathrm{p}_{\|\left.\right|^{-}}\right.$ $\left.\mathrm{p}_{\perp}\right) \mu_{0} / \mathrm{B}^{2}$, where $\mathrm{p}_{\|}$and $\mathrm{p}_{\perp}$ are the plasma pressures parallel and perpendicular to $\mathbf{B}$. Figures $5 \mathrm{a}$ and $\mathrm{b}$ show the (roughly) tangential $\mathrm{v}_{x}$ and $\mathrm{v}_{z}$ components $\left(\mathrm{v}_{y}\right.$ being approximately normal to the MP) of the predicted (red) and observed (black) flows.

The agreement between predicted and observed flows is remarkable, even for crossings that are far (more than $30 \mathrm{~min}$ ) from the reference time. The FTE flows also agree with the prediction. It is immediately clear from this comparison that all but one complete crossing (at 11:00 UT) in this interval observed reconnection jets at or very close to the predicted Alfvén velocity. Disagreement with prediction at other times occurred when the spacecraft are either in the inner part of the BL (and no longer in or near the RD) or in the magnetosphere.

To illustrate this point further, Figures $5 \mathrm{c}-\mathrm{d}$ show the comparison for measurements that have density $>7 \mathrm{~cm}^{-3}$ (roughly half of the magnetosheath density). This condi- tion ensures that the comparison is made only across the RD (Phan et al., 2001). With this density threshold the agreement is excellent throughout, including the MP at 11:00 UT and the FTE at 11:30 UT. Thus, the complete MP crossing at 11:00 UT, where jets were not observed, turned out to be a case where the crossing was too fast and hence no ion measurements were made within the MP. Thus, this analysis indicates that reconnection jets were detected at all MP crossings that are resolved by the ion measurements. It also demonstrates the robustness of the conclusion since the analysis is not sensitive to where the magnetosheath reference time is selected. Note that this analysis on a long stretch of data based on a single reference point is possible only because of the extreme steadiness of the IMF.

\subsection{Shear-stress balance test in the deHoffmann-Teller frame (Walén test)}

In this section we perform the Walén test in the deHoffmannTeller (HT) frame to assess quantitatively the level of agreement between reconnection prediction of the presence of an RD at the MP (Levy et al., 1964) and the observed flow acceleration. The result of this analysis has been shown by Bosqued et al. (2001) for one MP crossing and for the FTE at 11:30 UT. Here we show the results for all complete or nearcomplete MP crossings which occurred between 10:25 and 11:40 UT. The crossings before this time are mostly partial BL crossings from the magnetosphere where the MP current layer is not encountered. The Walén test cannot be performed on such events, although the similarity in the plasma flow direction and speed before and after 10:30 UT suggest that the jets are caused by the same mechanism.

In what follows we will first briefly describe the Walén test procedure. We will then illustrate the method and the findings with two MP events, the FTE at 11:30 UT, and a train of small amplitude FTEs. Table 1 summarizes the results of the analysis of the $16 \mathrm{MP}$ and FTE events. The method employed here was developed by Sonnerup et al. (1987). Phan et al. (2001) discussed the appropriate data interval to be used in such an analysis.

For a rotational discontinuity at the MP (Levy et al., 1964), the reconnection flow is Alfvénic in the deHoffmann-Teller (HT) frame of reference and follows the Walén relation (Sonnerup et al., 1987):

$\mathbf{v}-\mathbf{V}_{H T}= \pm(1-\alpha) \mathbf{B}\left[\mu_{0} \rho_{1}\left(1-\alpha_{1}\right)\right]^{-1 / 2}$,

where $\mathbf{V}_{H T}$ is the deHoffmann-Teller velocity.

The existence of a finite $\mathrm{B}_{N}$ at the MP requires field lines on both sides of the MP to move together. In this scenario there must be a reference frame (the HT frame) which slides along the MP with the field-line velocity. In this frame, the convective electric field vanishes $\left(\mathbf{E}_{c}=-\mathbf{v} \times \mathbf{B}=0\right)$, i.e. the flows are field aligned on the two sides of the MP.

In practice, the HT frame for a set of plasma and field measurements across the MP can be found as the reference frame in which the mean square of the convective electric field, $\mathrm{D}=<\left|\left(\mathbf{v}-\mathbf{V}_{H T}\right) \times \mathbf{B}\right|^{2}>$, is as small as possible (Sonnerup et 
Table 1. Summary or HT and Walén analyses on complete MP current layer crossings and FTEs.

\begin{tabular}{|c|c|c|c|c|c|c|c|c|c|}
\hline event & MP interval & $\begin{array}{c}\text { HT } \\
\text { slope }\end{array}$ & $\begin{array}{c}\mathrm{HT} \\
\mathrm{R} \\
\end{array}$ & $\mathrm{D} / \mathrm{D}_{0}$ & $\mathrm{~V}_{\mathrm{HT}, \mathrm{GSE}}$ & $\begin{array}{l}\text { Walen } \\
\text { slope }\end{array}$ & $\begin{array}{c}\text { Walen } \\
\text { R }\end{array}$ & $\mathrm{N}_{\mathrm{i}, \text { sheath }}$ & $\begin{array}{c}\# \\
\text { data }\end{array}$ \\
\hline \multicolumn{10}{|c|}{ Magnetopause } \\
\hline 1 & $10: 29: 12-10: 32: 48$ & 1.01 & 0.97 & 0.014 & $(-276,123,159)$ & 0.90 & 0.96 & 13.4 & 162 \\
\hline 2 & $10: 33: 00-10: 35: 45$ & 1.01 & 0.96 & 0.024 & $(-274,126,170)$ & 0.96 & 0.96 & 13.4 & 126 \\
\hline 3 & $10: 35: 30-10: 41: 28$ & 1.01 & 0.95 & 0.022 & $(-241,128,156)$ & 0.96 & 0.96 & 14.4 & 267 \\
\hline 4 & $10: 41: 40-10: 43: 58$ & 1.01 & 0.98 & 0.015 & $(-256,127,159)$ & 0.91 & 0.93 & 14.4 & 105 \\
\hline 5 & $10: 45: 32-10: 48: 33$ & 1.01 & 0.95 & 0.023 & $(-256,144,168)$ & 0.96 & 0.93 & 12.7 & 135 \\
\hline 6 & $10: 48: 00-10: 50: 49$ & 1.01 & 0.97 & 0.018 & $(-243,122,158)$ & 0.73 & 0.93 & 12.7 & 126 \\
\hline 7 & $10: 50: 3$ & 1.01 & 0.95 & 0.02 & $(-248,137,168)$ & 0.98 & 0.96 & 13.1 & 87 \\
\hline 8 & $10: 52: 30-10: 55: 20$ & 1.01 & 0.95 & 0.028 & $(-224,112,140)$ & 0.64 & 0.92 & 13.1 & 126 \\
\hline 9 & 10:54:56 & 1.01 & 0.94 & 0.026 & $(-254,136,16$ & 0.98 & 0.94 & 12.1 & 48 \\
\hline 10 & 10:59:10- & 1.03 & 0.87 & 0.048 & $(-146,55,105$ & 0.01 & 0.03 & 12.1 & 45 \\
\hline 11 & $11: 02: 48-11: 04: 24$ & 1.00 & 0.99 & 0.008 & $(-240,161,159)$ & 0.88 & 0.99 & 11.8 & 72 \\
\hline \multicolumn{10}{|l|}{ FTE } \\
\hline 12 & $11: 07: 50-11: 27: 00$ & 1.02 & 0.96 & 0.029 & $(-231,141,143)$ & 0.84 & 0.98 & 15.3 & 861 \\
\hline 13 & $11: 30: 34-11: 31: 04$ & 1.00 & 1.00 & 0.0 & $(-267,184,109)$ & 0.92 & 0.97 & 17.2 & 24 \\
\hline 14 & $11: 31: 40-11: 33: 00$ & 1.01 & 0.97 & 0.026 & $(-226,157,157)$ & 1.00 & 0.98 & 17.2 & 60 \\
\hline 15 & $12: 08: 48-12: 09: 40$ & 1.00 & 0.99 & 0.005 & $(-203,169,122)$ & 0.94 & 1.00 & 18.8 & 39 \\
\hline 16 & 12:10:04-12:11:09 & 1.00 & 1.00 & 0.007 & $(-209,161,117)$ & 0.97 & 0.99 & 18.8 & 51 \\
\hline
\end{tabular}

al., 1987; Khrabrov and Sonnerup, 1998). The angle bracket $<\ldots>$ denotes an average of an enclosed quantity over a set of measurements. The velocity $\mathbf{v}$ for which $\mathrm{D}(\mathbf{v})$ is a minimum is the deHoffmann-Teller velocity, $\mathbf{V}_{H T}$. The ratio $\mathrm{D} / \mathrm{D}_{0}$, where $\mathrm{D}_{0}=<\mid\left(\mathbf{v} \times\left.\mathbf{B}\right|^{2}>\right.$, is used as a measure of the quality of the HT frame. For a good HT frame $\mathrm{D} / \mathrm{D}_{0}$ should be small $(\ll 1)$ (Sonnerup et al., 1987).

\subsubsection{Individual examples}

Figure 6 shows the scatter plots of each GSE x, y, z component of the flow velocity in the HT frame versus the Alfvén velocity for two consecutive MP crossings (crossings 2 and 3 in Figs. 5a and f), an isolated FTE (crossing 14) and a train of small FTEs (crossing 12). Details of the results are given in Table 1. All 4 events have a good HT frame, indicated by their slopes and correlation coefficients being close to unity and $\mathrm{D} / \mathrm{D}_{0}<0.03$.

For the two MP crossings (panels (a) and (b)), the flow speed in the HT frame is $96 \%$ of the Alfvén speed for both events, and the correlation coefficient, $\mathrm{R}$, is 0.96 for both events as well. The positive slopes of the regression lines imply that the normal magnetic field points earthward (i.e. $\mathrm{B}_{N}<0$ ), consistent with the $\mathrm{X}$-line being below the spacecraft.

For the isolated FTE and the FTE train, the flow in the HT frame is $100 \%$ and $84 \%$ of the Alfvén speed, respectively, with an excellent correlation coefficient of 0.98 for both.

\subsubsection{Analysis on all complete MP current layer crossings and FTEs}

Table 1 summarizes the results of the analyses on all MP current layer crossings and FTEs after 10:25 UT. The crossing numbers and the MP intervals in the table are marked in Figs. 5a and f (except for crossings 15 and 16 which are not shown). With the exception of Crossing 10, which was shown in Sect. 4.2 to be a rapid crossing of the MP with no ion measurements in the MP, the Walén relation is well satisfied. Good deHoffmann-Teller frames are found for all events (slope and correlation coefficient are close to unity, and $\left.\mathrm{D} / \mathrm{D}_{0} \ll 1\right)$. The flow speed in the HT frame is $90 \%$ of the Alfvén speed, on average, for the $10 \mathrm{MP}$ events and the correlation coefficient $\mathrm{R}$ between the two quantities is, on average, 0.95 , indicating that both the speed and direction of the observed flows are in close agreement with the prediction, despite the fact that the analysis assumes 1-D MP structures and the Cluster/HIA ion moments are computed with the assumption that all ions are $\mathrm{H}^{+}$.

For the FTE at 11:30 UT, Bosqued et al. (2001) obtained a Walén slope of 0.87 . Their analysis interval included both the entry and exit of the FTE. If one divides the interval into inbound and outbound intervals, one obtains Walén slopes of 1.0 and 0.92 for the inbound and outbound intervals, respectively, i.e. the Walén relation is better satisfied.

Although the series of FTE (crossing 12) satisfy the Walén relation reasonably well, these are not complete crossings of the MP, thus the significance of the result is uncertain.

\subsection{Summary of Walén analyses}

We first demonstrated in a qualitative sense the Alfvénic nature of the jets, followed by two quantitative analyses. The Walén analysis in the HT frame is the most rigorous of the three methods and provides a quantitative measure of the agreement between prediction and observation, but its result could be somewhat sensitive to the exact data interval chosen (Phan et al., 2001). On the other hand, the success of the remarkably simple time series prediction in Sect. 4.2, based on a single reference point, has demonstrated the robustness of the conclusion that the enhanced flows at the MP and the FTE at 11:30 UT are produced by reconnection. 

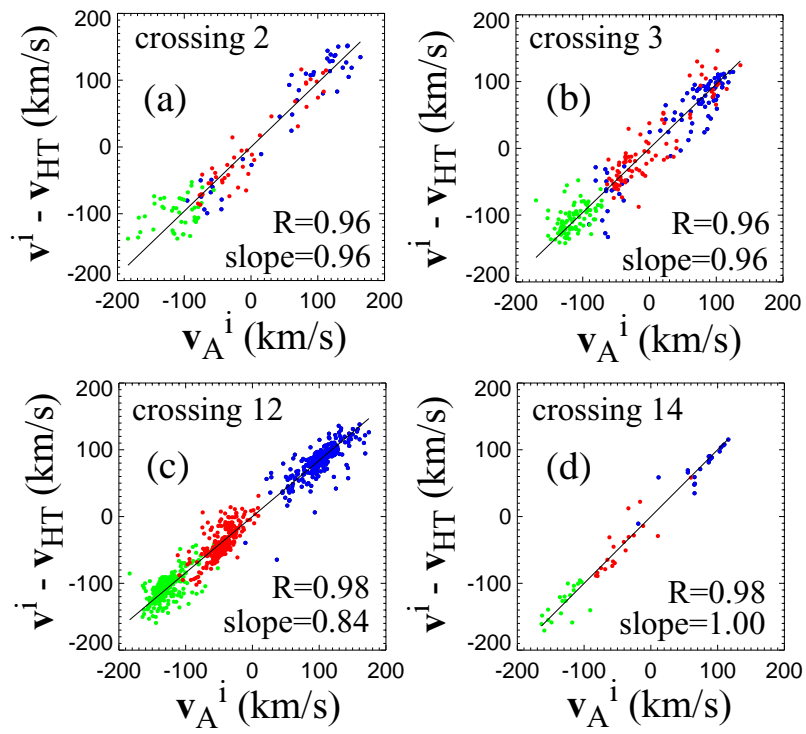

Fig. 6. Spacecraft 1 GSE ion velocity in the HT frame versus the Alfvén velocity for (a) crossing 2, (b) crossing 3, (c) series of smaller amplitude FTEs at 11:05-11:25 UT, (d) FTE at 11:30 UT. The blue, green, and red dots denote the $\mathrm{x}, \mathrm{y}$, and $\mathrm{z}$ components, respectively.

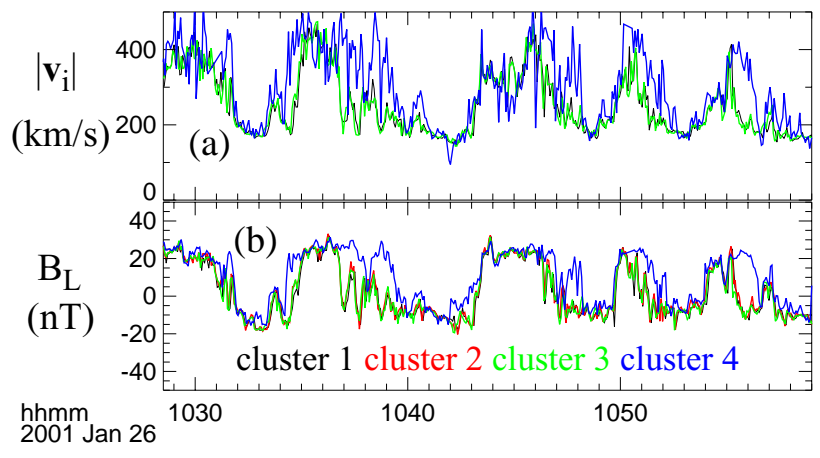

Fig. 7. (a) Overlay of spacecraft 1,3, and 4 ion flow speed, (b) overlay of spacecraft 1-4 magnetic field $\mathrm{B}_{L}$ component in the boundary normal coordinate system with $L$ pointing approximately in the GSM z direction.

\section{Discussions}

\subsection{Implication for continuous reconnection}

In Sect. 3 we showed the repeated encounters with plasma jets at the MP by the Cluster spacecraft over a period of $2 \mathrm{~h}$. The flow speed versus density profile (Fig. 4) indicated that plasma jets were detected at all MP/outer BL crossings that are resolved by the ion measurements. In Sect. 4, the Walén test was performed to demonstrate that the jet velocity and direction are consistent with reconnection. These findings suggest that reconnection was operating continuously over a period of $2 \mathrm{~h}$.

However, because a single Cluster spacecraft only spent a brief amount of time in the MP, one could not rule out the possibility that reconnection ceases when the spacecraft is not in the MP. In other words, the onset of reconnection could conceivably cause the MP to move, resulting in a crossing. With a single spacecraft one could never be sure. But with the multi-spacecraft following each other through the MP one could investigate whether reconnection signatures were detected by all spacecraft crossing the MP consecutively and therefore rule out the possibility that reconnection stops when a spacecraft leaves the MP. The multi-spacecraft measurements would also extend the total spacecraft residence time in the MP.

Figure 7 shows the velocity traces from spacecraft 1,3 , and 4 and magnetic field traces from all 4 spacecraft. The configuration of the spacecraft on this day is such that spacecraft 1,2, and 3 are in the same plane tangential to the MP and spacecraft 4 is closer to the Earth (see Fig. 1). Thus, traces from spacecraft 1,2, and 3 are nearly identical, while spacecraft 4 provides the separation along the MP normal. Jets are detected by the spacecraft residing in the MP even when the others are outside (see, for example, 10:39, 10:48 and 10:56 UT). If we combine the jet observations from all 3 spacecraft, we find that for more than half of the time during this 2-h interval, at least one spacecraft was in the MP and detected jets. Ideally, one would like to have at least one spacecraft in the MP at any given time so that the MP can be monitored continuously, which is not possible with a limited number of spacecraft. Thus, the most conservative conclusion from the observations presented here is that reconnection occurs at least $50 \%$ of the time in this 2 -h interval. In reality the percentage is likely to be closer to $100 \%$, since the jets are seen at every MP crossing by all spacecraft (except the rapid crossing at 11:00 UT where no ion measurements were made in the MP/outer BL).

It should be emphasized that the continuous detection of Alfvénic reconnection jets does not imply that reconnection proceeds at a steady rate. The jet speed is always Alfvénic independent of the reconnection rate (as long as the rate does not drop to zero). In fact, the presence of convecting bulges discussed in the next section may suggest that the reconnection rate is modulated.

5.2 Traveling bulges: a consequence of variable reconnection rate?

In Sect. 3 we pointed out that most of the MP crossings in the 2-h interval are partial crossings. This indicates that the crossings are not caused by the inward-outward motion of a uniformly thin MP/BL. Rather, they are caused by traveling plasma blobs bulging into both the magnetosheath and the magnetosphere. What process generates these blobs cannot be deduced directly from the present observations. However one can exclude the passage of magnetic islands with alternate $\mathrm{X}$-points and $\mathrm{O}$-points as an explanation, because the flow jets do not reverse direction. Therefore, these blobs are not generated by multiple $\mathrm{X}$-line reconnection. A possible interpretation is that these blobs are the result of a variable reconnection rate (e.g. Scholer, 1988), although the 
observational constraint is that this rate never drops to zero. The important implication of such an interpretation is that even when the IMF is extremely steady, the reconnection rate may not be steady and the MP is not 1-D.

\subsection{Stable X-line(s) versus random-and-patchy reconnec-} tion or convecting multiple $\mathrm{X}$-lines

The persistence of the jet direction and its detection at every MP implies that the reconnection site remains southward and sunward of the spacecraft at all times. This finding would be inconsistent with patchy and random reconnection where the reconnection sites are small patches distributed over a large range of latitudes and local times. It is also inconsistent with convecting multiple $\mathrm{X}$-lines which would have resulted in reversals of plasma jets (in the magnetosheath bulk velocity frame). Because all the spacecraft were on the same side of the reconnection site at all times, it is not possible to determine from the observations whether there is a single or multiple X-lines south and sunward of the spacecraft nor the precise stability of the reconnection site(s). However, it is noted that both anti-parallel and component merging models predict a single stable X-line in the Southern Hemisphere on the dusk flank MP - more than $9 R_{E}$ from the spacecraft for the present IMF $\left(\mathrm{B}_{y}<0\right)$ condition, which is consistent with (1) the X-line always being below the spacecraft and (2) the implied negative $\mathrm{B}_{N}$ (from the postive Walén slope) at the Cluster MP location. The agreement with either model would imply that the large-scale reconnection configuration is determined by the IMF, not by the local MP conditions.

\subsection{Success of Walén test}

In Sects. 4.2 and 4.3, we showed that the plasma velocity at the MP is in close agreement with the reconnection prediction, despite the fact that the Walén analysis assumes 1-D MP structures and the Cluster/HIA ion moments used in this study are computed with the assumption that all ions are $\mathrm{H}^{+}$. Now we discuss the implications of this successful Walén test.

In terms of the 1-D stationary structure, while the time dependent nature of the MP is not known in this case, the implied blobs (Sect. 5.2) would indicate a severe violation of the 1-D assumption. The success of the Walén test thus suggests that the shear stress balance does not depend strongly on the 1-D assumption.

In terms of the possible presence of heavy ions $\left(\mathrm{O}^{+}\right.$or $\mathrm{He}^{++}$) that could affect the HIA ion moments and therefore the Walén test (Paschmann et al., 1986; Puhl-Quinn and Scudder, 2000) the observed $\mathrm{O}^{+}$number density is $\sim 2 \%$ of the total density. At this low $\mathrm{O}^{+}$density, the effect is negligible (Paschmann et al., 1986). This is consistent with the successful Walén test for all events on this day.

The use of ions instead of electrons (which are better tied to the magnetic field) in the HT and Walén analyses has been invoked (Scudder et al., 1999) to explain the sub-Alfvénic flows reported in previous studies (Paschmann et al., 1986;
Phan et al., 1996). We note that in the present case, the MP current density is of the order of $50 \mathrm{nA} / \mathrm{m}^{2}$. This implies an ion-electron differential motion of $\sim 20 \mathrm{~km} / \mathrm{s}$, which is small compared to the $200 \mathrm{~km} / \mathrm{s}$ flow enhancements at the MP. Since this MP current density value is rather typical (Dunlop et al., 2002), the use of ions instead of electrons is unlikely to be the source for previous sub-Alfvénic flow cases.

Another interesting implication is that if either of the large-scale component or anti-parallel merging models is correct, the X-line on the dusk side of the magnetosphere would be in the Southern Hemisphere, which means it is more than $9 R_{E}$ away from Cluster. However, the plasma jets satisfy the Walen relation applied across the local MP. Thus, this finding emphasizes the fact that most of the plasma transfer across the MP occurs over an extended region, far from the $\mathrm{X}$-line.

Finally, the plasma $\beta$ (Fig. 2i) in the magnetosheath is near unity and stable throughout the 2-h MP pass. Good agreement with the Walén relation at this $\beta$ value is consistent with the previous findings of Paschmann et al. (1986), Scurry et al. (1994) and Phan et al. (1996). Why the flows should be more Alfvénic at low $\beta$ than at high $\beta$ is not well understood.

\subsection{Absence of D-shaped ion distributions in reconnection jets}

The existence of the D-shaped ion distributions at the MP, a predicted kinetic effect of reconnection (Cowley, 1982), had been reported in a number of studies (e.g. Gosling et al., 1990; Fuselier et al., 1991; Smith and Rodgers, 1991; Bauer et al., 1998; Phan et al., 2001). These distributions have the predicted low-energy cutoff along a constant $\mathrm{v}_{/ /}$at precisely the deHoffmann-Teller velocity. Their detections provide quantitative evidence for reconnection which complement the observations of the fluid signatures of reconnection, namely the Alfvénic jets.

On occasion, both fluid and kinetic signatures of reconnection have been seen in the same events. However, in a systematic survey of these signatures at the MP, Bauer et al. (1998) found that more often than not, fluid signatures (Alfvénic flows) are observed without particle signatures ("D-shaped" ion distributions), and vice versa. This is a surprising finding since one would expect all fluid and kinetic signatures to be present in any reconnection events.

In the present study we demonstrated the existence of Alfvénic flows at all the MP crossings. One thus expects to detect $\mathrm{D}$-shaped ion distributions in the jets. We have examined every ion distribution measured in the jets and found that, contrary to the expectation, none of the distributions displays the expected D-shape with low-energy cutoff at the HT velocity. Examples are shown in Fig. 8, where we display consecutive distributions measured during an MP crossing from the magnetosheath into the MP. It is seen that the distributions in the MP jets (panels $\mathrm{d}-\mathrm{h}$ ) are nearly isotropic in the bulk velocity frame, with no low-energy cutoffs at the HT velocity (the black dot in all panels). This finding does not 

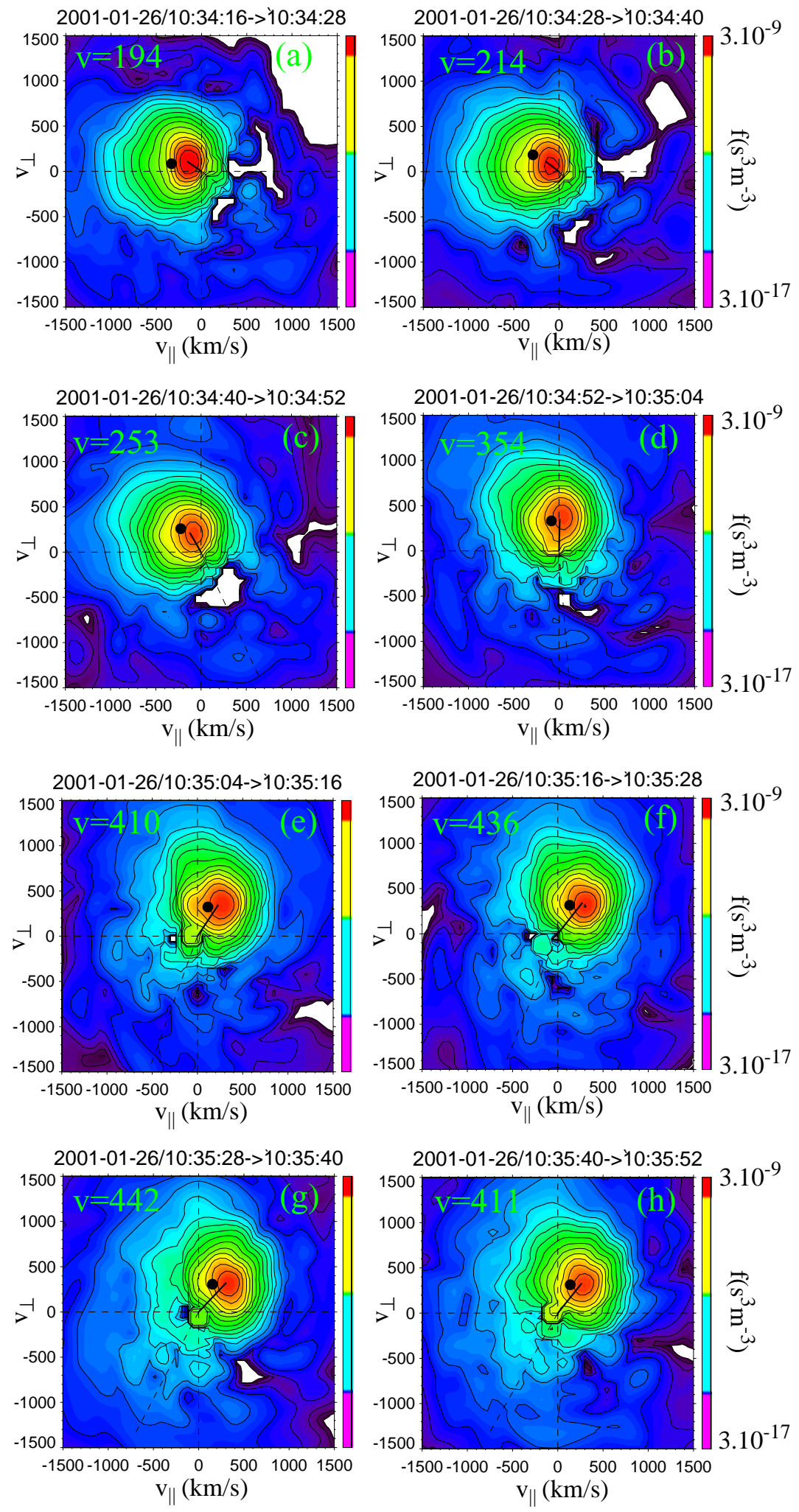

Fig. 8. Two-dimensional cuts of the 3-D ion distributions through velocity space that contains the directions of the magnetic field (to the right) and $\mathbf{E} \times \mathbf{B}$ (upward), with 12-s sampling time. The projection of the sunward direction is marked by the black dashed line. Bulk velocity is marked by the short black line. The 8 consecutive ion distributions were taken as the spacecraft moved from the magnetosheath (a)-(c) across the MP/BL (d)-(h). The black dot in all panels denote the projection of the HT velocity. No D-shaped distributions are observed in this or any other reconnection jets on this pass. 
depend on the location within the MP/BL where the distributions are sampled. Phan et al. (2001) suggested that the Dshaped distributions are only present on the magnetosheath edge of the MP because the plasma there had crossed the MP locally. However, in this event the D-shape distributions are absent across the entire MP.

The presence of the D-shaped distributions in some reconnection events (from previous reports) but not in others is a mystery. Figure 9 displays a clear D-shaped distribution detected on 18 March 2002 by Cluster in a reconnection event poleward of the cusp during northward IMF (Phan et al., 2003). One noted difference between the 26 January 2001 and 18 March 2002 events is that for the 18 March 2002 event, the jets (and the D-shaped) distributions were detected relatively close to the $\mathrm{X}$-line (since the $\mathrm{X}$-line drifted past the spacecraft), whereas in the present (26 January 2001) case, the $\mathrm{X}$-line is likely to be more than $9 R_{E}$ away. Whether the distance to the $\mathrm{X}$-line is a determining factor remains to be seen.

\subsection{Relationship between FTE and MP blobs}

The ion properties of the isolated FTE at 11:30 UT are similar to those of partial MP crossings (which we interpreted as evidence for bulges) in terms of the density, temperature and the presence of magnetospheric $\mathrm{O}^{+}$. Flows in the FTE are directed in the same direction as the MP jets and satisfy the Walén relation. The magnetic field rotation across the FTE is also similar to that at the MP. These similarities suggest that this FTE is simply a partial crossing of the MP, and not an independent structure that convects along the MP. The one drastic difference is the strongly enhanced magnetic field strength in the FTE ( $>50 \mathrm{nT}$ ) that is not present at the MP crossings, indicating that the bulging associated with the FTE is more severe (see also Paschmann et al., 1982).

\section{Summary}

On 26 January 2001, the Cluster spacecraft encountered the high-latitude dusk flank MP/BL multiple times during a period of two hours. The crossings of these regions occurred under stable and negative IMF $\mathrm{B}_{z}$ and $\mathrm{B}_{y}$, with $\mathrm{B}_{x} \sim 0$. The magnetosheath $\beta$ was close to unity throughout the 2-h interval. The key observations and interpretations can be summarized as follows:

1. Plasma jets were detected at all but one MP crossing. The lone exception is a case where there were no measurements within the MP/outer BL. The jet speed and direction at most of the MP crossings are in excellent agreement with the 1-D model of the reconnecting MP, with an average Walén slope of 0.90 . The Cluster spacecraft spent a combined $\sim 1 \mathrm{~h}$ in the MP (in this 2 -h period) during which time the reconnection jets were observed by all spacecraft. We interpret these observations as evidence for continuous reconnection at the MP over a period of $2 \mathrm{~h}$.

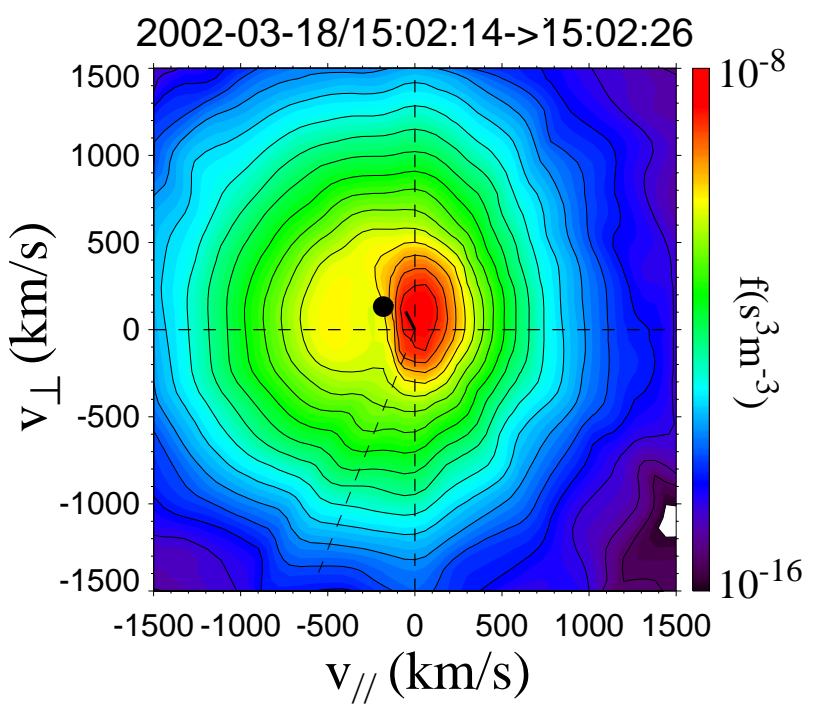

Fig. 9. Two dimensional cuts of the 3-D ion distributions in a tailward of cusp reconnection event on 18 March 2002 (Phan et al., 2003) for comparison. The D-shape distribution, with the lowenergy cutoff along a constant $\mathrm{v} / /$ at the HT velocity, is clearly present.

2. Magnetospheric $\mathrm{O}^{+}$are present in every plasma jet, with density similar to that in the magnetosphere. This is consistent with the interpretation of continuous reconnection where the reconnected field lines are freshly opened, as opposed to open field lines that linger after the cessation of reconnection.

3. The majority of the MP/BL crossings, both inbound and outbound, are partial crossings. This is not consistent with the simple inward-outward motion of a uniformly thin MP/BL but indicates instead that the crossings are caused by plasma blobs convecting along the MP. The presence of the blobs could suggest that although reconnection seems to be continuous (i.e. never ceases), the reconnection rate may be modulated.

4. The jets are directed persistently in the same northward and anti-sunward direction over the 2 -h period. This implies that the reconnection site remained southward and sunward of the spacecraft at all times. This finding is inconsistent with patchy and random reconnection where the reconnection sites are small patches randomly distributed over a large range of latitudes and local times (Nishida et al., 1989). It is also inconsistent with convecting multiple X-lines (Shi et al., 1998) which would have resulted in reversals of plasma jets. It is noted that both anti-parallel and component merging models predict a stable X-line in the Southern Hemisphere on the dusk flank MP - more than $9 R_{E}$ from the spacecraft - for the present IMF $\left(\mathrm{B}_{y}<0\right)$ condition which would be consistent with the observed fact that the $\mathrm{X}$-line was always below the spacecraft. 
5. Reconnection signatures were observed at the MP where the magnetic shear across the MP was $\sim 100^{\circ}$ (i.e. far from the anti-parallel situation). However, this should not be taken as evidence for component merging since it is the shear at the $\mathrm{X}$-line, not at the local MP, that matters. In this case, if either of the component or anti-parallel merging models is valid, the X-line would be more than $9 R_{E}$ away where the shear could be substantially different from the local shear. Similarly, the fact that we observe reconnection signatures in the Northern Hemisphere on the dusk flank for negative IMF $\mathrm{B}_{y}$ does not contradict the large-scale (component or anti-parallel merging) models which predict the $\mathrm{X}$-line location to be in the opposite (southern) hemisphere for this IMF orientation. This is because as long as reconnection is initiated and remains active (at the $\mathrm{X}$ line), the plasma transfer (and acceleration) occurs over an extended region of the MP.

6. The observed plasma jet speed and direction agree with the Walén relation to high precision, despite the fact that the Walén analysis assumes 1-D MP structures while the presence of blobs seem to indicate that this assumption is severely violated. Thus, our finding suggests that the results of the shear stress balance are not highly sensitive to the violation of the 1-D assumption.

7. The MP current density at these MP crossings is of the order of $50 \mathrm{nA} / \mathrm{m}^{2}$ which is rather typical (Dunlop et al., 2002). This translates to a differential electron-ion motion of $20 \mathrm{~km} / \mathrm{s}$, compared to the $200 \mathrm{~km} / \mathrm{s}$ flow acceleration. Thus, the effect of MP current on the HT and Walén analyses is minimal.

8. Contrary to the kinetic prediction, none of the ion distributions observed in the present reconnection jets is D-shaped (with low-energy cutoff along a constant $\mathrm{v}_{/ /}$ at the HT velocity). The reason for the occurrence of D-shaped distributions in some reconnection events (reported in previous studies) but not in others is not known.

9. The electric field fluctuations at the reconnecting MP are larger than in the magnetosheath proper, but their amplitudes never exceed $20 \mathrm{mV} / \mathrm{m}$. The EFW electric field was sampled at $25 \mathrm{sample} / \mathrm{s}$ on this day. The absence of intense electric fields may be consistent with the X-line being far away (more than $9 R_{E}$ ) from the local MP.

Acknowledgements. We thank the principal investigators of ACE MAG and SWEPAM experiments for making their data available. We also thank M. Øieroset for her helpful comments on the manuscript. Part of the work was performed when T. Phan was visiting MPE Garching. This research is supported in part by NASA grants NAG5-11987, NAG5-10131, and NAG5-11944.

Topical Editor T. Pulkkinen thanks I. Coleman and another referee for their help in evaluating this paper.

\section{References}

Avanov. L. A., Smirnov, V. N., Waite Jr., J. H., et al.: High-latitude magnetic reconnection in sub-Alfvénic flow: Interball tail observations on May 29, 1996, J. Geophys. Res., 106, 12, 29491$29502,2001$.

Balogh, A., Carr, C. M., Acuna, M. H., et al.: The Cluster magnetic field investigation: overview of in-flight performance and initial results, Ann. Geophys., 19, 1207-1217, 2001.

Bauer, T. M., Paschmann, G., Sckopke, N., Baumjohann, W., Treumann, R. A., and Phan, T. D.: AMPTE-IRM observations of particle and fields at the dayside low-latitude magnetopause, Geospace Mass and Energy Flow: Results from the International Solar-Terrestrial Physics Program, edited by Horwitz, J. L., Gallagher, D. L., and Peterson, W. K., Geophysical Monograph, 104, 51-72, 1998.

Bosqued, J. M., Phan, T. D., Dandouras, I., et al.: Cluster observations of the high-latitude magnetopause and cusp: initial results from the CIS ion instruments, Ann. Geophys., 19, 1545-1566, 2001.

Cowley, S. W. H.: The causes of convection in the Earth's magnetosphere: A review of developments during the IMS, Rev. Geophys. Space Phys., 20, 531-565, 1982.

Cowley, S. W. H.: Evidence for the occurrence and importance of reconnection between the Earth's magnetic field and the interplanetary magnetic field, Magnetic Reconnection in Space and Laboratory Plasmas, edited by Hones, E. W., Geophysical Monograph, 30, 375-378, 1984.

Dunlop, M. W., Balogh, A., Glassmeier, K.-H., and Robert, P.: Four-point Cluster application of magnetic field analysis tools: The Curlometer, J. Geophys. Res., 107, A11, pp. SMP 24-1 to 24-13, CiteID 1385, doi:10.1029/2001JA005088, 2002.

Farrugia, C. J., Sandholt, P. E., Denig, W. F., and Torbert, R. B.: Observation of a correspondence between poleward moving auroral forms and stepped cusp ion precipitation, J. Geophys. Res., 103, 9309-9315, 1998.

Frey, H. U., Phan, T. D., Fuselier, S. A., and Mende, S. B.: Continuous magnetic reconnection at Earth's magnetopause, Nature, 626, 533-537, 2003.

Fuselier, S. A., Klumpar, D. M., and Shelly, E. G.: Ion reflection and transmission during reconnection at the Earth's subsolar magnetopause, Geophys. Res. Lett., 18, 139-141, 1991.

Gosling, J. T., Asbridge, J. R., Bame, S. J., Feldman, W. C., Paschmann, G., Sckopke, N., and Russell, C. T.: Evidence for quasi-stationary reconnection at the dayside magnetopause, J. Geophys. Res., 87, 2147-2158, 1982.

Gosling, J. T., Thomsen, M. F., Bame, S. J., Onsager, T. G., and Russell, C. T.: The electron edge of the low-latitude boundary layer during accelerated flow events, Geophys. Res. Lett., 17, 1833-1836, 1990.

Gosling, J. T., Thomsen, M. F., Bame, S. J., Elphic, R. C., and Russell, C. T.: Observations of reconnection of interplanetary and lobe magnetic field lines at the high-latitude magnetopause, J. Geophys. Res., 96, 14 097-14 106, 1991.

Guftassen, G., Andre, M., Carozzi, T., et al.: First results of electic field and density observations by Cluster EFW based on initial months of operation, Ann. Geophys., 19, 1219-1240, 2001.

Hudson, P. D.: Discontinuities in an anisotropic plasma and their identification in the solar wind, Planet. Space Sci., 18, 1611$1622,1970$. 
Khrabrov, A. V. and Sonnerup, B. U. Ö.: DeHoffmann-Teller analysis, Analysis methods for multi-spacecraft data, edited by Paschmann, G. and Daly, P. W., ISSI Scientific Report, SR-001, 221-248, 1998.

Levy, R. H., Petschek, H. E., and Siscoe, G. L.: Aerodynamic aspects of the magnetospheric flow, AIAA J., 2, 2065, pp. 64-87, 1964.

Lockwood, M., Lanchester, B. S., Frey, H. U., et al.: IMF control of cusp proton emission intensity and dayside convection: implications for component and anti-parallel reconnection, Ann. Geophys., 21, 955-982, 2003.

Mozer, F. S., Bale, S. D., and Phan, T. D.: Evidence of diffusion regions at a subsolar magnetopause crossing, Phys. Rev. Lett., 89, 015002-1-015002-4, 2002.

Nishida, A.: Can random reconnection at the magnetopause produce the low-latitude boundary layer?, Geophys. Res. Lett., 16, 227-230, 1989.

Onsager, T. G., Scudder, J. D., Lockwood, M., and Russell, C. T.: Reconnection at the high-latitude magnetopause during northward interplanetary magnetic field conditions, J. Geophys. Res., 106, 11, 25 467-25 488, 2001.

Paschmann, G., Sonnerup, B. U. Ö., Papamastorakis, I., et al.: Plasma acceleration at the Earth's magnetopause: Evidence for magnetic reconnection, Nature, 282, 243-246, 1979.

Paschmann, G., Haerendel, G., Papamastorakis, I., Sckopke, N., Bame, S. J., Gosling, J. T., and Russell, C. T.: Plasma and magnetic field characteristics of magnetic flux transfer events, J. Geophys. Res., 87, 2159-2168, 1982.

Paschmann, G., Baumjohann, W., Sckopke, N., Papamastorakis, I., and Carlson, C. W.: The magnetopause for large magnetic shear: AMPTE/IRM observations, J. Geophys. Res., 91, 11 099$11115,1986$.

Paschmann, G., Baumjohann, W., Sckopke, N., Phan, T. D., and Luehr, H.: Structure of the dayside magnetopause for low magnetic shear, J. Geophys. Res., 98, 13 409-13 422, 1993.

Phan, T. D., Paschmann, G., and Sonnerup, B. U. Ö.: Low-latitude magnetopause and boundary layer for high magnetic shear: 2 . Occurrence of magnetic reconnection, J. Geophys. Res., 101, 7817-7828, 1996.

Phan, T.-D., Larson, D., McFadden, J., et al.: Low-latitude dusk flank magnetosheath, magnetopause, and boundary layer for low magnetic shear: Wind observations, J. Geophys. Res., 102, 19883-19896, 1997.

Phan, T. D., Kistler, L. M., Klecker, B., et al.: Extended magnetic reconnection at the Earth's magnetopause from detection of bidirectional jets, Nature, 404, 848-850, 2000.
Phan, T. D., Sonnerup, B. U. Ö., and Lin, R. P.: Fluid and kinetic signatures of reconnection at the dawn tail magnetopause: Wind observations, J. Geophys. Res., 106, 25 489-25 502, 2001.

Phan, T. D., Frey, H. U., Frey, S., et al.: Simultaneous Cluster and IMAGE observations of cusp reconnection and auroral proton spot for northward IMF, Geophys. Res. Lett., 30(10), pp 16-1 to 16-4, CiteID 1509, doi:10.1029/2003GL016885, 2003.

Pinnock, M., Chisham, G., Coleman, I. J., Freeman, M. P., Hairston, M., and Villain, J. P.: The location and rate of dayside reconnection during an interval of southward interplanetary magnetic field, Ann. Geophys., 21, 1467-1482, 2003.

Puhl-Quinn, P. and Scudder, J. D.: Effects of composition on Walén tests using E/Z spectrometer data, J. Geophys. Res., 105, 76177627, 2000.

Rème, H., Aoustin, C., Bosqued, J. M., et al.: First multispacecraft ion measurements in and near the earth's magnetosphere with the identical CLUSTER Ion Spectrometry (CIS) Experiment, Ann. Geophys., 19, 1303-1354, 2001.

Russell, C. T. and Elphic, R. C.: Initial ISEE magnetometer results: Magnetopause observations, Space Sci. Rev., 22, 681-715, 1978.

Scholer, M.: Magnetic flux transfer at the magnetopause based on a single X line burst reconnection, Gephys. Res. Lett., 15, 291294, 1988.

Scudder, J. D., Puhl-Quinn, P., Mozer, F. S., Russell, C. T., and Ogilvie, K.: Generalized Walén tests through Alfvén waves and rotational discontinuities using electron flow velocities, J. Geophys. Res., 104, 19817-19833, 1999.

Scurry, L., Russell, C. T., and Gosling, J. T.: Geomagnetic activity and the beta dependence of the dayside reconnection rate, J. Geophys. Res., 99, 14811-14 814, 1994.

Shi, Y., Wu, C. C., Lee, L. C., et al.: A study of multiple X line reconnection at the dayside magnetopause, Geophys. Res. Lett., 15, 295-298, 1988.

Smith, M. F. and Rodgers, D. J.: Ion distributions at the dayside magnetopause, J. Geophys. Res., 96, 11 617-11 624, 1991.

Sonnerup, B. U. Ö., Paschmann, G., Papamastorakis, I., Sckopke, N., Haerendel, G., Bame, S. J., Asbridge, J. R., Gosling, J. T., and Russell, C. T.: Evidence for magnetic reconnection at the Earth's magnetopause, J. Geophys. Res., 86, 10 049-10 067, 1981.

Sonnerup, B. U. Ö., Papamastorakis, I., Paschmann, G., and Luehr, H.: Magnetopause properties from AMPTE/IRM observations of the convective electric field: Method development, J. Geophys. Res., 92, 12 137-12 159, 1987. 